\title{
Association of Hashimoto's thyroiditis with thyroid cancer
}

\author{
G Azizi, J M Keller ${ }^{1}$, M Lewis, K Piper ${ }^{2}$, D Puett ${ }^{3}$, K M Rivenbark and C D Malchoff ${ }^{4}$ \\ Wilmington Endocrinology, 1717 Shipyard Boulevard, Suite 220, Wilmington, North Carolina 28403, USA \\ ${ }^{1}$ Wilmington Pathology Associates, 1915 South 17th Street, Suite 100, Wilmington, North Carolina 28401, USA \\ ${ }^{2}$ Children's Hospital Colorado, 13123 East 16th Avenue, Aurora, Colorado 80045, USA \\ ${ }^{3}$ Carolina Arthritis, 1710 South 17th Street, Wilmington, North Carolina 28401, USA \\ ${ }^{4}$ University of Connecticut Health Center, 263 Farmington Avenue, Farmington, Connecticut 06030, USA
}

Correspondence should be addressed to G Azizi

Email

azizi@wilmingtonendo.com

\begin{abstract}
This prospective study investigates the relationship between Hashimoto's thyroiditis (HT) and thyroid cancer (TC) in patients with thyroid nodules (TNs). We prospectively examined 2100 patients with 2753 TNs between January 5, 2010 and August 15, 2013. A total of 2023 patients with 2669 TNs met the inclusion criteria of TN $\geq 5 \mathrm{~mm}$ and age $\geq 18$ years. Each patient had blood drawn before fine-needle aspiration biopsy (FNAB) for the following measurements: TSH, free thyroxine, free tri-iodothyronine, thyroid peroxidase antibody (TPOAb), and antithyroglobulin antibody (TgAb). Diagnosis of TC was based on pathology analysis of thyroidectomy tissue. The associations of TC with the independent variables were determined by univariate and multivariate logistic regression analysis and reported as adjusted odds ratio (OR) with $95 \% \mathrm{Cl}$. A total of 248 malignant nodules were found in 233 patients. There was an association of TC with both increased serum TgAb concentration and age $<45$ years. An elevated serum $\operatorname{TgAb}$ concentration was found in $10.2 \%$ of patients (182 of 1790) with benign nodules as compared with $20.6 \%$ of patients (48 of 233 ) with malignant nodules $(P \leq 0.0001)$. TgAb $(\mathrm{OR}=2.24: \mathrm{Cl}=1.57,3.19)$ and $\mathrm{TSH} \geq 1 \mu \mathrm{IU} / \mathrm{ml}$ (OR $(95 \% \mathrm{CI})$ ) OR: $1.49(1.09,2.03)$ were significant predictors of TC in multivariate analysis controlling for age and gender. TC was not associated with serum concentrations of TPOAb. In patients with TN, elevated serum concentration of TgAb and TSH $\geq 1 \mu \mathrm{lU} / \mathrm{ml}$ are independent predictors for TC. The association between HT and TC is antibody specific.
\end{abstract}

Key Words

- Hashimoto's thyroiditis

thyroid cancer

- thyroid nodule

- FNAB

- TgAb
Endocrine-Related Cancer (2014) 21, 845-852

\section{Introduction}

Hashimoto's thyroiditis (HT) is the most common autoimmune thyroid disease and the most common cause of hypothyroidism (Jankovic et al. 2013). Epidemiological and histological data indicate that thyroid cancer (TC) frequently occurs in the context of one of the most common autoimmune thyroid diseases, HT, and that TC is frequently infiltrated by inflammatory-immune cells (Guarino et al. 2010).

HT is characterized by infiltration of the thyroid gland by inflammatory cells. This often leads to hypothyroidism due to destruction and eventual fibrous replacement of the parenchymal tissue. The relationship between HT and papillary carcinoma (PC) was first proposed by Dailey et al. (1955). Since this initial description, the association between the diseases has been repeatedly reported and highly debated in the literature and remains controversial (Cunha et al. 2011).

A relationship between chronic inflammation and cancer was first proposed by Virchow (1863) and has been sustained by clinical and epidemiological evidence.

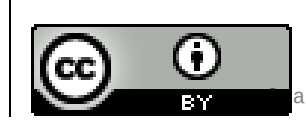


The most compelling evidence is the association between: i) intestinal chronic inflammatory diseases (Crohn's disease and ulcerative rectocolitis) and adenocarcinoma of the colon; ii) chronic HBV or HCV hepatitis and liver carcinoma; iii) Heliobacter pylori-induced chronic gastritis and gastric carcinoma; iv) asbestosis and mesothelioma; v) chronic obstructive pulmonary disease and lung cancer; and vi) scleroderma and carcinoma of the breast and lung (Guarino et al. 2010, Joseph et al. 2014).

Two recent retrospective studies have reported a positive association between HT and TC in patients presenting with thyroid nodules (TNs). In these two studies, antithyroglobulin antibody ( $\mathrm{TgAb}$ ), but not thyroid peroxidase antibody (TPOAb), was an independent risk factor for TC (Kim et al. 2010, Azizi \& Malchoff 2011).

Based on these previous retrospective studies, we hypothesized that the association of HT with TC is antibody specific. Since a retrospective study's design may be subject to ascertainment bias and assay heterogeneity, we chose to further investigate the relationship between HT and TC by prospectively examining this relationship in TN patients using a multivariate approach to account for the possible influence of other variables including the levels of thyroid-stimulating hormone (TSH).

\section{Patients and methods}

\section{Patients}

The inclusion criteria were the presence of a single or multiple TNs $\geq 5 \mathrm{~mm}$ and age $\geq 18$ years.

We prospectively evaluated 2100 patients with 2753 TNs from January 5, 2010 to August 15, 2013. All TNs were evaluated with a high-resolution ultrasound (US), fineneedle aspiration biopsy (FNAB), and, when indicated, by tissue pathology. All patients were evaluated by a single endocrinologist ( $G$ A) with more than 15 years of experience in thyroid US and ultrasound-guided FNAB.

The study protocol was approved by the Institutional Review Board of the New Hanover Regional Medical Center, Wilmington, NC. All patients gave written informed consent.

\section{Biochemical assays}

At the time of initial US examination, the following factors were ascertained in all study subjects: gender, age, and number of US-determined TN. Treatment with any TSH-altering medication was documented. All patients had their blood drawn before FNAB for the following measurements: TSH, free thyroxine, free tri-iodothyronine, TPOAb, and TgAb. All measurements were performed by LabCorp (LabCorp Research Triangle Park-Center for Molecular Biology and Pathology, Esoteric Division, Research Triangle Park, NC, USA). Both TPOAb and $\operatorname{TgAb}$ levels were measured using Immulite 2000 technology by Siemens Medical Solutions Diagnostics (Brewster, NY, USA) utilizing purified antigen (TPO) immobilized to insoluble beads in a solid phase, enzymelabeled chemiluminescent sequential immunometric assay. The reference range for TPOAb and $\mathrm{TgAb}$ levels was $0-34$ and $0-40 \mathrm{IU} / \mathrm{ml}$ respectively. The analytical sensitivity for TPOAb and TgAb levels was 5 and $2.2 \mathrm{IU} / \mathrm{ml}$ respectively. Serum TSH level was measured at LabCorp by an electrochemiluminescence immunoassay developed by Roche Diagnostic. The reference range for TSH was $0.45-4.5 \mu \mathrm{IU} / \mathrm{ml}$. Hypothyroidism is defined as TSH $>4.5 \mu \mathrm{IU} / \mathrm{ml}$ without thyroid medication and in patients with a known history of hypothyroidism on thyroid hormone replacement. Hyperthyroidism is defined as TSH $<0.45 \mu \mathrm{IU} / \mathrm{ml}$ without medication and in patients with prior history of hyperthyroidism on antithyroid medication.

\section{FNAB procedure}

Before the FNAB, we obtained written informed consent for the procedure. The FNAB was performed under sterile conditions with US guidance to confirm accurate needle placement. Three passes were made of each lesion using 27 -gauge needles. If there was no sample on visual inspection, we then used a larger needle (25-gauge). Onsite adequacy was not performed in this study. The samples were submitted for cytologic evaluation in accordance with the Bethesda system for reporting thyroid cytopathology, resulting in diagnostic Bethesda categories (BC) I (nondiagnostic or unsatisfactory), II (benign), III (atypia of undetermined significance or follicular lesion of undetermined significance), IV (follicular neoplasm or suspicious for follicular neoplasm), $\mathrm{V}$ (suspicious for malignancy), or VI (malignant) (Cibas \& Ali 2009). For patients with BC I cytology, a second FNAB was offered.

\section{Selection for thyroidectomy}

Surgical resection was recommended for patients with FNAB results that were positive for malignancy, highly suspicious for PC or follicular neoplasm, or follicular cells of undetermined significance. In addition, thyroid surgery was also recommended for patients with two

Published by Bioscientifica Ltd. 
non-diagnostic or benign FNABs with two or more US features suggestive of TC (irregular margins, microcalcifications, hypoechoic pattern) or increased size.

\section{Statistical analysis}

The statistical analysis was performed by Dr M N Kuchibhatla (Associate Professor of Biostatistics and Director for Center for Aging, Duke University Department of Statistics) using SPSS/SAS program (SAS Institute, 2009. Statistical applications software: Release 9.2. SAS Institute, Inc., Cary, NC, USA). Means and s.D. were used to summarize quantitative variables, while frequencies and percentages were used to summarize qualitative data. Bivariate associations with TC were examined using nonparametric Wilcoxon tests for quantitative variables and $\chi^{2}$ tests for categorical variables. Univariate association of independent variables (age, gender, elevated $\mathrm{TgAb}$, elevated TPO, euthyroid normal antibodies, hyperthyroid, hypothyroid, multinodular goiter (MNG) gland, single nodule gland, thyroid medication, history of head/neck radiation, and family history of TC) on diagnosis of cancer was determined using logistic regression. Multivariable logistic regressions adjusting for age and gender were used to examine associations between TC and each of the variables and serum concentrations of $\mathrm{TSH}, \mathrm{TgAb}$, and TPOAb. A probability of $<0.05$ was considered statistically significant.

\section{Results}

\section{Patients and TNs}

Figure 1 summarizes the 2100 patients with 2753 TNs who were evaluated between January 5, 2010 and August 15, 2013. There were 77 patients with 84 TNs who were not included in the statistical analysis for one or more of the following reasons: patient moved away, patient refused recommended surgery, or patient did not return for follow-up. Of the 77 patients, 37 patients were excluded BC I, 27 were BC III, ten were BC IV, one was BC V, and two were BC VI.

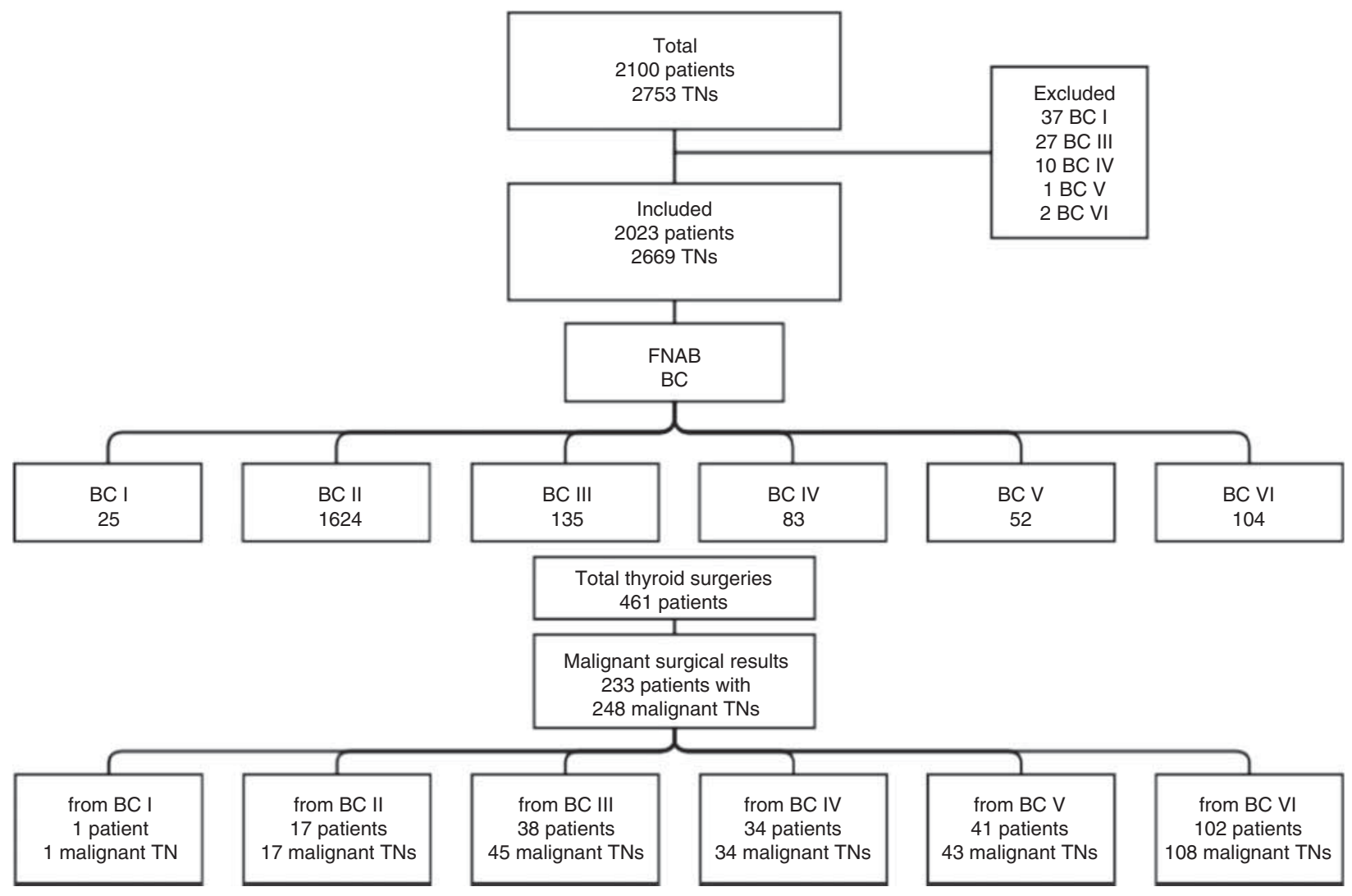

Figure 1

Flow chart for FNAB and surgical outcome.

http://erc.endocrinology-journals.org DOI: $10.1530 /$ ERC-14-0258
(C) 2014 The authors Printed in Great Britain
Published by Bioscientifica Ltd. 
The remaining 2023 patients with 2669 TNs were included in the statistical analysis. There were 1150 TNs that were $<10 \mathrm{~mm}$ in greatest diameter, and the remaining 1519 TNs were $\geq 10 \mathrm{~mm}$. There were 1348 patients who had FNAB of a single TN and 675 patients who had FNAB of two or more TNs.

\section{FNAB cytology}

Figure 1 summarizes the FNAB cytopathology results of the 2023 patients. For patients with more than one nodule, the highest grade of BC was reported. 1624 patients were BC II, 135 patients were BC III, 83 patients were $\mathrm{BC} I V, 52$ patients were $\mathrm{BC} \mathrm{V}$, and 104 patients were BC VI. Among patients with BC I, 25 remained in the study because they had surgery.

\section{Surgical pathology}

Thyroidectomy was performed on 461 patients. Of these, 374 had abnormal FNAB (BC III, IV, V, or VI) and 25 had non-diagnostic FNAB (BC I). 62 patients with benign FNAB (BC II) had surgery due to worrisome US features or a size large enough to warrant surgery. Of the 461 patients who had surgery, 233 patients with 248 malignant TNs were diagnosed with TC. Figure 1 summarizes the number of patients assigned to each FNAB BC category.

TC was histologically confirmed in 233 patients: 45 patients had single nodule gland and 188 patients had MNG. Among those patients with MNG, 121 (64\%) TCs were in dominant TN and $67(36 \%)$ of TC were in non-dominant TN.

Of the 248 malignant TNs, 149 were PC, 83 were follicular variant of PC, four were medullary carcinoma, and 12 were follicular carcinoma. From the 248 malignant TNs, 104 were $<10 \mathrm{~mm}$ diameter in size and 144 were $\geq 10 \mathrm{~mm}$ diameter in size. There were 44 follicular adenomas on surgical pathology in this study.

\section{Univariate associations with TC and surgery}

As expected, young age was a risk factor for TC (Tables 1 and 2 respectively). The mean age of patients with benign nodules was 49.05 years (15.93\%) and was greater than that for patients with malignant nodules, which was 45.33 years $(15.29 \%)(P=0.0007)$. The malignancy rate among males was higher than females, but did not reach statistical significance most likely due to high number of female patients (84\%) in this study.

There is an association between TC and TgAb. Serum $\mathrm{TgAb}$ concentration was elevated above the normal range in $20.6 \%(n=48)$ of the TC patients as compared with $10.17 \%(n=182)$ of the patients with benign nodule $(P<0.0001)$. In contrast, TC was not associated with TPOAb concentration. Serum TPOAb concentration was elevated in $31.33 \%(n=73)$ of the TC patients and $26.7 \%$ ( $n=478)$ of the benign nodule patients $(P=0.1356)$.

There was a trend for TC to be associated with family history of TC and with head/neck radiation, but these did not reach statistical significance.

Table 2 demonstrates that there was no significant association of surgical intervention with any of the biochemical variables, indicating that knowledge of serum antibody and TSH concentrations did not influence the investigator's decision to resect a nodule. Therefore, no selection bias for surgical resection influenced the final association of TC with TgAb.

Table 1 Univariate analysis: related variables with thyroid cancer for all patients enrolled in the study

\begin{tabular}{|c|c|}
\hline Variable & $\begin{array}{c}\text { No cancer } \boldsymbol{n}(\%) / \text { mean (s.D.) } \\
(N=1790)\end{array}$ \\
\hline Age (mean/s.D.) & $49.05(15.93 \%)$ \\
\hline \multicolumn{2}{|l|}{$N(\%)$} \\
\hline Female & $1503(83.97 \%)$ \\
\hline Elevated TgAb & $182(10.17 \%)$ \\
\hline Elevated TPOAb & $478(26.7 \%)$ \\
\hline Euthyroid normal antibodies & $935(52.23 \%)$ \\
\hline Hyperthyroid & $189(10.56 \%)$ \\
\hline Hypothyroid & $516(28.83 \%)$ \\
\hline MNG gland & $1502(83.91 \%)$ \\
\hline Single nodule gland & $288(16.09 \%)$ \\
\hline Thyroid medication & $508(28.43 \%)$ \\
\hline History of head/neck radiation & $24(1.37 \%)$ \\
\hline Family history of TC & $90(5.03 \%)$ \\
\hline
\end{tabular}

\begin{tabular}{c} 
Cancer $\boldsymbol{n}(\%) /$ mean $($ s.o. $)$ \\
$(N=233)$ \\
\hline $45.33(15.29 \%)$ \\
$190(81.55 \%)$ \\
$48(20.6 \%)$ \\
$73(31.33 \%)$ \\
$114(48.93 \%)$ \\
$18(7.73 \%)$ \\
$72(30.9 \%)$ \\
$188(80.69 \%)$ \\
$45(19.31 \%)$ \\
$69(29.61 \%)$ \\
$6(2.59 \%)$ \\
$18(7.73 \%)$ \\
\hline
\end{tabular}

P value
0.0007

0.3467
$<0.0001$
0.1356
0.3419
0.1795
0.5118
0.2119
0.2119
0.7062
0.1556
0.2263


Table 2 Univariate analysis: related variables with thyroid surgery for all patients enrolled in the study

\begin{tabular}{|c|c|c|c|}
\hline Variable & $\begin{array}{l}\text { No surgery } \boldsymbol{n}(\%) / \text { mean (s.D.) } \\
\qquad(N=1582)\end{array}$ & $\begin{array}{l}\text { Surgery } \boldsymbol{n}(\%) / \text { mean (s.D.) } \\
\qquad(N=461)\end{array}$ & $P$ value \\
\hline Age (mean/s.D.) & $49.41(16.04)$ & $45.93(15.11)$ & $<0.0001$ \\
\hline$N(\%)$ & $1582(1582)$ & $461(461)$ & \\
\hline Female & $1318(84.38)$ & $375(81.34)$ & 0.1213 \\
\hline Elevated TgAb & $167(10.69)$ & 63 (13.67) & 0.0771 \\
\hline Elevated TPOAb & $433(27.72)$ & $118(25.6)$ & 0.3680 \\
\hline TSH concentration & $2.44(8.28)$ & $1.92(2.09)$ & 0.9482 \\
\hline Euthyroid normal antibodies & $804(51.47)$ & $245(53.15)$ & 0.5276 \\
\hline Hyperthyroid & $151(9.67)$ & $56(12.15)$ & 0.1226 \\
\hline Hypothyroid & $468(29.96)$ & $120(26.03)$ & 0.1024 \\
\hline MNG gland & $1305(83.55)$ & $385(83.51)$ & 0.9868 \\
\hline Single nodule gland & $257(16.45)$ & $76(16.49)$ & 0.9868 \\
\hline Thyroid medication & $455(29.19)$ & $122(26.46)$ & 0.2558 \\
\hline History of head/neck radiation & $23(1.47)$ & $8(1.74)$ & 0.6864 \\
\hline Family history of TC & $79(5.06)$ & $29(6.29)$ & 0.5838 \\
\hline
\end{tabular}

\section{Multivariate associations with TC}

In the multivariate analysis, controlling for age and gender, $\operatorname{TgAb}(\mathrm{OR}(95 \% \mathrm{CI}))$ : OR: $2.24(1.57,3.19)$ was a significant predictor of cancer while TPOAb (OR $(95 \% \mathrm{CI})$ ): OR: $1.19(0.88,1.61)$ was not (Table 3$)$. In the initial analysis for this study, when divided into four prespecified groups, TSH was not found to be a predictor of TC. In the multivariate analysis, none of the TSH groups were a risk factor for TC. TSH groups included: 0 to $0.45 \mu \mathrm{IU} / \mathrm{ml}$; $>0.45$ to $\leq 2 \mu \mathrm{IU} / \mathrm{ml} ;>2$ to $\leq 4.5 \mu \mathrm{IU} / \mathrm{ml}$; and the final TSH group was patients with TSH $>4.5 \mu \mathrm{IU} / \mathrm{ml}$. However, when we retrospectively repeated the analysis with a single cutoff, TSH $>1 \mu \mathrm{IU} / \mathrm{ml}$ was a predictor for higher risk for cancer (OR $(95 \% \mathrm{CI}))$ OR: $1.49(1.09,2.03)$. In an age and gender-adjusted multivariate logistic regression analysis of subjects who were not taking any TSH-altering medication, undetectable $\mathrm{TgAb}$ level remained a significant predictor of cancer (OR (95\% CI)): OR: 2.28 $(1.42,3.66)$.

Table 4 shows a detailed breakdown of all patients included in the study. We divided patients with normal $\mathrm{TgAb}$ level by those with undetectable $\mathrm{TgAb}$ level (Ref: 0 ) and those with detectable $\operatorname{TgAb}$ level, but still within normal range $(>0$ to $<40$ ). We had 1706 patients with undetectable TgAb level; among those 175 patients had TC and 1531 patients had no cancer. We had 89 patients with TgAb level with detectable but, still within normal range; among those 15 had TC and 74 had no cancer. We then grouped patients with elevated TgAb levels by those with $\mathrm{TgAb}>40$ to $<200$ and patients with $\mathrm{TgAb} \geq 200$. In the first group, we had a total of 122 patients with 24 having cancer and 98 without TC. In the final group with $\operatorname{TgAb} \geq 200$, we had 106 patients. Among those patients, 19 had TC, and 87 had no cancer. Table 5 gives a detailed breakdown of the number of patients by TSH concentration.

\section{Discussion}

Our prospective study of patients with TN demonstrates that an elevated serum $\mathrm{TgAb}$ concentration is an independent predictor for TC. Serum TPOAb concentration was not a predictor of TC in either univariate or multivariate analyses.

This prospective study was undertaken to further investigate the risk of thyroid inflammation and TC. It confirms two retrospective studies that suggested this association $(2,22)$. For the study's assay, the normal

Table 3 Age and gender-adjusted multivariate logistic regression predicting cancer

\begin{tabular}{|c|c|c|c|}
\hline Variable & $\begin{array}{l}\text { Odds } \\
\text { ratio }\end{array}$ & $\begin{array}{c}95 \% \\
\text { Lower CL }\end{array}$ & $\begin{array}{c}95 \% \\
\text { Upper CL }\end{array}$ \\
\hline Thyroglobulin antibody & 2.24 & 1.57 & 3.19 \\
\hline $\begin{array}{l}\text { TPO antibody } \\
\text { TgAb level (Ref: } 0)\end{array}$ & 1.19 & 0.88 & 1.61 \\
\hline$>0$ to $<40$ & 1.70 & 0.95 & 3.03 \\
\hline$\geq 40$ to $<200$ & 2.05 & 1.27 & 3.31 \\
\hline$\geq 200$ & 1.89 & 1.12 & 3.19 \\
\hline TSH level (Ref: <1) & & & \\
\hline $\begin{array}{l}\geq 1 \\
\text { TSH level (Ref: } 0 \text { to } 0.45)\end{array}$ & 1.46 & 1.07 & 1.99 \\
\hline$>0.45$ to $\leq 2$ & 1.16 & 0.74 & 1.81 \\
\hline$>2$ to $\leq 4.5$ & 1.27 & 0.78 & 2.07 \\
\hline$>4.5$ & 1.23 & 0.65 & 2.35 \\
\hline
\end{tabular}

All patients in the study with the following variables: TgAb, TPOAb and TSH level, once in a single cutoff analysis and once in multigroup analysis.

Published by Bioscientifica Ltd. 
Table 4 Breakdown of patients by TgAb level in age and gender-adjusted multivariate logistic regression

\begin{tabular}{|c|c|c|c|c|c|}
\hline \multicolumn{6}{|c|}{ Cancer predicted by TgAb level } \\
\hline Frequency & Ref: 0 & $>0$ to $<40$ & $\geq 40$ to $<200$ & $\geq 200$ & Total \\
\hline No cancer & 1531 & 74 & 98 & 87 & 1790 \\
\hline Cancer & 175 & 15 & 24 & 19 & 233 \\
\hline Total & 1706 & 89 & 122 & 106 & 2023 \\
\hline
\end{tabular}

A detailed breakdown of all patients included in the study. All patients were divided into two groups: those with undetectable TgAb (Ref: 0), and those with detectable but normal range $\operatorname{TgAb}(>0$ to $<40)$. The elevated antibody group was then further broken down into the following ranges: $\geq 40$ to $<200$ and $\geq 200$.

reference range for $\mathrm{TgAb}$ concentration was 0 to $40 \mathrm{IU} / \mathrm{ml}$. In the multivariate analysis, we found that patients with detectable but normal $\mathrm{TgAb}$ concentrations ( $>0$ to $<40 \mathrm{IU} / \mathrm{ml})$ had an (OR (95\% CI)): OR: $1.70(0.95,3.03)$. This finding suggests that lowering the cutoff value for $\mathrm{TgAb}$ or TPOAb may reduce the false negative misclassifications, as noted by Spencer (2011) and Spencer et al. (2011). This statistically non-significant trend for association with TC would be of interest to investigate in a larger study with greater statistical power to determine if the risk of TC with increasing $\mathrm{TgAb}$ is present at any $\mathrm{TgAb}$ concentration or if there is a threshold $\mathrm{TgAb}$ concentration below which there is no increased risk of TC.

There were 114 patients with TC who had normal thyroid function and normal thyroid antibodies (TPOAb $<34 \mathrm{IU} / \mathrm{ml}$ and $\mathrm{TgAb}<40 \mathrm{IU} / \mathrm{ml})$. In this group, 17 patients (15\%) had histopathologic changes in HT. This finding may indicate that the prevalence of HT in TC might be higher than expected.

A recent review by Jankovic et al. (2013) has revealed significant differences in the prevalence and the risk ratio of TC in HT specimens obtained via FNAB vs thyroidectomy. All eight FNAB studies (Crile \& Hazard 1962, Holm et al. 1985, Carson et al. 1996, Erdogan et al. 2009, Matesa-Anić et al. 2009, Anil et al. 2010, Mukasa et al. 2011) with negative association between HT and TC have a low prevalence of TC, $0-2.9 \%$, but the prevalence of surgical thyroidectomy studies ranges from 9.4 to $36 \%$ (Ott et al. 1985, Singh et al. 1999, Cipolla et al. 2005, Kurukahvecioglu et al. 2007, Larson et al. 2007, Repplinger et al. 2008, Bradly et al. 2009, Mazokopakis et al. 2010, Siriweera \& Ratnatung 2010, Jankovic et al. 2013).

The prevalence of TC in this prospective study was $11.5 \%$ for patients and $9.2 \%$ for TNs, which is within the 5-15\% TC risk expected for TNs (Cooper et al. 2009). Approximately $41 \%$ of the TCs were $<10 \mathrm{~mm}$ in diameter, which is not unexpected for a US study that relies heavily on US for nodule detection. The risk of TC for each FNAB $\mathrm{BC}$ group was similar to the expected risk (Cooper et al. 2009). Since the population under investigation is similar to those reported in the literature, it seems unlikely that a selection bias, error in FNAB classification, or unique risk factor is influencing the reported associations.

The effect of TSH, family history, and external radiation were examined. We did observe a statistically significant effect of TSH on TC risk in TN patients when we retrospectively analyzed our results using a serum TSH cutoff (TSH $>1 \mu \mathrm{IU} / \mathrm{ml}$ ) that had not been prespecified. As reviewed by McLeod et al. (2012), the association of TSH with TC is weak when the effect of autoimmune thyroid disease is incorporated into the multivariate analysis (Gul et al. 2010, Jin et al. 2010). When divided into four groups, TSH was not a predictor for TC. Where TSH is divided into four groups (with $<0.45 \mu \mathrm{IU} / \mathrm{ml}$ as the reference group) the lack of effect may be due to inadequate power. This result was seen in two previously published studies (Kim et al. 2010, Azizi \& Malchoff 2011). Similarly, the lack of an effect of family history and radiation exposure on the risk of TC is due to the small number of patients with these risk factors, limiting the power of this study. The association of young age and trend for association with male gender are known associations that are reproduced in this study.

The association of TgAb with malignancy in patients with nodule has been found in some studies (Kim et al. 2010, Azizi \& Malchoff 2011), but not all (Boelaert 2009). Boelaert evaluated TPOAb, but not TgAb (Boelaert et al. 2006). Haymart et al. $(2008,2009)$ reported that independent of age, higher TSH level was associated with increased incidence of TC and extrathyroidal extension of disease. In their study, neither TPOAb nor $\mathrm{TgAb}$ status was reported. The failure of some studies to identify this relationship may be related to the variability of the $\mathrm{TgAb}$ assay. $\operatorname{TgAb}$ assays are highly variable as a consequence of many factors, including the heterogeneity of $\mathrm{TgAb}$ (Latrofa et al. 2012).

Table 5 Breakdown of patients by TSH level in age and gender-adjusted multivariate logistic regression

\begin{tabular}{|c|c|c|c|c|c|}
\hline \multicolumn{6}{|c|}{ Cancer predicted by TSH level } \\
\hline Frequency & Ref: 0 to 0.45 & $>0.45$ to $\leq 2$ & $>2$ to $\leq 4.5$ & $>4.5$ & Total \\
\hline No cancer & 232 & 995 & 438 & 125 & 1790 \\
\hline Cancer & 26 & 128 & 61 & 18 & 233 \\
\hline Total & 258 & 1123 & 499 & 143 & 2023 \\
\hline
\end{tabular}

A detailed breakdown of all patients included in the study. All patients were divided based on TSH level.

Published by Bioscientifica Ltd. 
The relationship between inflammation and TC is complex and still not completely understood (Guarino et al. 2010). Both retrospective studies and now this prospective study of $\mathrm{TN}$ patients suggest that the association of HT with TC is antibody specific (Kim et al. 2010, Azizi \& Malchoff 2011). The mechanism leading to this association is not known. TgAb may have a tumorigenic effect or be closely associated with a specific tumorigenic inflammatory response. Alternatively, the thyroglobulin molecule in TC may be more antigenic due to altered processing or an acquired or germline mutation in the primary structure. It is of interest that the TPOAb is not associated with a risk of TC. TPOAb is believed to fix complement and is a more sensitive marker for HT and hypothyroidism than TgAb. Perhaps the cytotoxic effect of TPOAb is that it protects against the tumorigenic effect of thyroid inflammation. It is also of interest that the development of malignancy in scleroderma is also antibody specific. Further investigations into this phenomenon of antibody specificity may lead to a better understanding of tumorigenesis (Joseph et al. 2014).

The present study has several strengths. The biochemical measurements and patient phenotypic data were all collected prospectively to eliminate selection bias, which is confirmed by the lack of association of surgical intervention with biochemical analysis. All measurements of TSH, TgAb and TPOAb were made at the same laboratory and using the same methodology for each patient to eliminate any interference from variability of different assay methodologies. Finally, only $3.7 \%$ of the initial 2100 patients seen were excluded from the study due to previously discussed reasons. This small fraction is unlikely to affect the outcome of this study. Since this is a cross-sectional association study, it does not directly address the mechanism that explains the association of $\mathrm{TgAb}$ and TC.

In summary, elevated serum TgAb level was associated with an increased risk of TC in patients with TN. In single cutoff analysis, TSH $\geq 1 \mu \mathrm{IU} / \mathrm{ml}$ is a significant predictor of TC. Serum TPO was not associated with TC. We conclude that the association of HT with TC is antibody specific.

\section{Declaration of interest}

The authors declare that there is no conflict of interest that could be perceived as prejudicing the impartiality of the research reported.

\section{Funding}

This research did not receive any specific grant from any funding agency in the public, commercial, or not-for-profit sector.

\section{Acknowledgements}

The authors acknowledge Maggie M Kuchibhatla, PhD (Duke University, Durham, NC) for performing the statistical analysis and for expert statistical advice. They thank the Wilmington Endocrinology staff, especially Brandy Lundberg and Caroline Hoppe, for their efforts and dedication to this prospective study.

\section{References}

Anil C, Goksel S \& Gursoy A 2010 Hashimoto's thyroiditis is not associated with increased risk of thyroid cancer in patients with thyroid nodules: a single-center prospective study. Thyroid 20 601-606. (doi:10.1089/ thy.2009.0450)

Azizi G \& Malchoff CD 2011 Autoimmune thyroid disease: a risk factor for thyroid cancer. Endocrine Practice 17 201-209. (doi:10.4158/ EP10123.OR)

Boelaert K 2009 The association between serum TSH concentration and thyroid cancer. Endocrine-Related Cancer 16 1065-1072. (doi:10.1677/ ERC-09-0150)

Boelaert K, Horacek J, Holder RL, Watkinson JC, Sheppard MC \& Franklyn JA 2006 Serum thyrotropin concentration as a novel predictor of malignancy in thyroid nodules investigated by fine-needle aspiration. Journal of Clinical Endocrinology and Metabolism 91 4295-4301. (doi:10.1210/jc.2006-0527)

Bradly D, Reddy V, Prinz RA \& Gattuso P 2009 Incidental papillary carcinoma in patients treated surgically for benign thyroid diseases. Surgery 146 1099-1104. (doi:10.1016/j.surg.2009.09.025)

Carson H, Castelli M \& Gattuso P 1996 Incidence of neoplasia in Hashimoto's thyroiditis: a fine-needle aspiration study. Diagnostic Cytopathology 14 38-42. (doi:10.1002/(SICI)1097-0339(199602) $14: 1<38::$ AID-DC8 $>3.0$. CO; 2 -R)

Cibas ES \& Ali SZ 2009 The Bethesda system for reporting thyroid cytopathology. American Journal of Clinical Pathology 132 658-665. (doi:10.1309/AJCPPHLWMI3JV4LA)

Cipolla C, Sandonato L, Graceffa G, Fricano S, Torcivia A, Vieni S, Latteri S \& Latteri MA 2005 Hashimoto's thyroiditis coexistent with papillary thyroid carcinoma. American Surgeon 71 874-878.

Cooper DS, Doherty GM, Haugen BR, Kloos RT, Lee SL, Mandel SJ, Mazzaferri EL, McIver B, Pacini F, Schlumberger M et al. 2009 Revised American Thyroid Association management guidelines for patients with thyroid nodules and differentiated thyroid cancer. Thyroid 19 1167-1214. (doi:10.1089/thy.2009.0110)

Crile GJ \& Hazard JB 1962 Incidence of cancer in struma lymphomatosa. Surgery, Gynecology \& Obstetrics 115 101-103.

Cunha LL, Ferreira RC, Marcello MA, Vassallo J \& Ward LS 2011 Clinical and pathological implications of concurrent autoimmune thyroid disorders and papillary thyroid cancer. Journal of Thyroid Research $\mathbf{2 0 1 1}$ 387062. (doi:10.4061/2011/387062)

Dailey ME, Lindsay S \& Skahen R 1955 Relation of thyroid neoplasms to Hashimoto disease of the thyroid gland. A.M.A. Archives of Surgery 70 291-297. (doi:10.1001/archsurg.1955.01270080137023)

Erdogan M, Erdem N, Cetinkalp S, Ozgen AG, Saygılı F, Yilmaz C, Tuzun M \& Kabalak T 2009 Demographic, clinical, laboratory, ultrasonographic, and cytological features of patients with Hashimoto's thyroiditis: results of a university hospital of 769 patients in Turkey. Endocrine $\mathbf{3 6}$ 486-490. (doi:10.1007/s12020-009-9258-z)

Guarino V, Castellone MD, Avilla E \& Melillo RM 2010 Thyroid cancer and inflammation. Molecular and Cellular Endocrinology 321 94-102. (doi:10.1016/j.mce.2009.10.003)

Gul K, Ozdemir D, Dirikoc A, Oguz A, Tuzun D, Baser H, Ersoy R \& Cakir B 2010 Are endogenously lower serum thyroid hormones new predictors for thyroid malignancy in addition to higher serum thyrotropin? Endocrine 37 253-260. (doi:10.1007/s12020-010-9316-6) 
Haymart MR, Repplinger DJ, Leverson GE, Elson DF, Sippel RS, Jaume JC \& Chen H 2008 Higher serum thyroid stimulating hormone level in thyroid nodule patients is associated with greater risks of differentiated thyroid cancer and advanced tumor stage. Journal of Clinical Endocrinology and Metabolism 93 809-814. (doi:10.1210/jc.2007-2215)

Haymart MR, Glinberg SL, Liu J, Sippel RS, Jaume JC \& Chen H 2009 Higher serum TSH in thyroid cancer patients occurs independent of age and correlates with extrathyroidal extension. Clinical Endocrinology $\mathbf{7 1}$ 434-439. (doi:10.1111/j.1365-2265.2008.03489.x)

Holm LE, Blomgren H \& Lowhagen T 1985 Cancer risks in patients with chronic lymphocytic thyroiditis. New England Journal of Medicine 312 601-604. (doi:10.1056/NEJM198503073121001)

Jankovic B, Le KT \& Hershman JM 2013 Clinical Review: Hashimoto's thyroiditis and papillary thyroid carcinoma: is there a correlation? Journal of Clinical Endocrinology and Metabolism 98 474-482. (doi:10.1210/jc.2012-2978)

Jin J, Machekano R \& McHenry CR 2010 The utility of preoperative serum thyroid-stimulating hormone level for predicting malignant nodular thyroid disease. American Journal of Surgery 199 294-297. (doi:10.1016/ j.amjsurg.2009.08.028)

Joseph CG, Darrah E, Shah AA, Skora AD, Casciola-Rosen LA, Wigley FM, Boin F, Fava A, Thoburn C, Kinde I et al. 2014 Association of the autoimmune disease scleroderma with an immunologic response to cancer. Science 343 152-157. (doi:10.1126/science.1246886)

Kim ES, Lim DJ, Baek KH, Lee JM, Kim MK, Kwon HS, Song KH, Kang MI, Cha BY, Lee KW et al. 2010 Thyroglobulin antibody is associated with increased cancer risk in thyroid nodules. Thyroid 20 885-891. (doi:10.1089/thy.2009.0384)

Kurukahvecioglu O, Taneri F, Yuksel O, Aydin A, Tezel E \& Onuk E 2007 Total thyroidectomy for treatment of Hashimoto's thyroiditis coexisting with papillary thyroid carcinoma. Advances in Therapy 24 510-516. (doi:10.1007/BF02848773)

Larson SD, Jackson LN, Riall TS, Uchida T, Thomas RP, Qiu S \& Evers BM 2007 Increased incidence of well-differentiated thyroid cancer associated with Hashimoto's thyroiditis and the role of the PI3k/Akt pathway. Journal of the American College of Surgeons 204 764-773 discussion 773-5. (doi:10.1016/j.jamcollsurg.2006.12.037)

Latrofa F, Ricci D, Montanelli L, Rocchi R, Piaggi P, Sisti E, Grasso L, Basolo F, Ugolini C, Pinchera A et al. 2012 Lymphocytic thyroiditis on histology correlates with serum thyroglobulin autoantibodies in patients with papillary thyroid carcinoma: impact on detection of serum thyroglobulin. Journal of Clinical Endocrinology and Metabolism 97 2380-2387. (doi:10.1210/jc.2011-2812)

Matesa-Anić D, Matesa N, Dabelić N \& Kusić Z 2009 Coexistence of papillary carcinoma and Hashimoto's thyroiditis. Acta Clinica Croatica 48 9-12.

Mazokopakis EE, Tzortzinis AA, Dalieraki-Ott EI, Tsartsalis AN, Syros PK, Karefilakis CM, Papadomanolaki MG \& Starakis IK 2010 Coexistence of Hashimoto's thyroiditis with papillary thyroid carcinoma. A retrospective study. Hormones 9 312-317. (doi:10.14310/horm.2002.1282)

McLeod DS, Watters KF, Carpenter AD, Ladenson PW, Cooper DS \& Ding EL 2012 Thyrotropin and thyroid cancer diagnosis: a systematic review and dose-response meta-analysis. Journal of Clinical Endocrinology and Metabolism 97 2682-2692. (doi:10.1210/jc.2012-1083)

Mukasa K, Noh JY, Kunii Y, Matsumoto M, Sato S, Yasuda S, Suzuki M, Ito K \& Ito K 2011 Prevalence of malignant tumors and adenomatous lesions detected by ultrasonographic screening in patients with autoimmune thyroid diseases. Thyroid 21 37-41. (doi:10.1089/thy.2010.0050)

Ott RA, Calandra DB, McCall A, Shah KH, Lawrence AM \& Paloyan E 1985 The incidence of thyroid carcinoma in patients with Hashimoto's thyroiditis and solitary cold nodules. Surgery 98 1202-1206.

Repplinger D, Bargren A, Zhang YW, Adler JT, Haymart M \& Chen H 2008 Is Hashimoto's thyroiditis a risk factor for papillary thyroid cancer. Journal of Surgical Research 150 49-52. (doi:10.1016/j.jss.2007.09.020)

Singh B, Shaha AR, Trivedi H, Carew JF, Poluri A \& Shah JP 1999 Coexistent Hashimoto's thyroiditis with papillary thyroid carcinoma: impact of presentation, management and outcome. Surgery 126 1070-1077. (doi:10.1067/msy.2099.101431)

Siriweera EH \& Ratnatung NV 2010 Profile of Hashimoto's thyroiditis in Sri Lankans: is there an increased risk of ancillary pathologies in Hashimoto's thyroiditis. Journal of Thyroid Research 2010 1-5. (doi:10.4061/2010/124264)

Spencer CA 2011 Clinical review: clinical utility of thyroglobulin antibody $(\mathrm{TgAb})$ measurements for patients with differentiated thyroid cancers (DTC). Journal of Clinical Endocrinology and Metabolism 96 3615-3627. (doi:10.1210/jc.2011-1740)

Spencer C, Petrovic I \& Fatemi S 2011 Current thyroglobulin auto antibody $(\mathrm{TgAb})$ assays often fail to detect interfering $\operatorname{TgAb}$ that can result in the reporting of falsely low/undetectable serum Tg IMA values for patients with differentiated thyroid cancer. Journal of Clinical Endocrinology and Metabolism 96 1283-1291. (doi:10.1210/jc.2010-2762)

Received in final form 26 August 2014

Accepted 12 September 2014

Made available online as an Accepted Preprint

12 September 2014 http://erc.endocrinology-journals.org

DOI: 10.1530/ERC-14-0258
(C) 2014 The authors Printed in Great Britain
Published by Bioscientifica Ltd. 